\title{
Baseline urologic surgical skills among medical students: Differentiating trainees
}

\author{
Vishaal Gupta; ${ }^{*}$ Andrea G. Lantz, MD, FRCSC; ; Tarek Alzharani, MD;" Kirsten Foell, MD,;s \\ Jason Y. Lee, MD, FRCSC ${ }^{S}$
}

*Faculty of Medicine, University of Toronto, Toronto, ON; 'Department of Urology, Dalhousie University, Halifax, NS; §Division of Urology, St. Michael's Hospital and University of Toronto, Toronto, ON

Cite as: Can Urol Assoc J 2014;8(7-8):242-6. http://dx.doi.org/10.5489/cuaj.1807

Published online August 11, 2014.

\section{Abstract}

Introduction: Urology training programs seek to identify ideal candidates with the potential to become competent urologic surgeons. It is unclear whether innate technical ability has a role in this selection process. We aimed to determine whether there are any innate differences in baseline urologic technical skills among medical students.

Methods: Second-year medical students from the University of Toronto were recruited for this study and stratified into surgical and non-surgical cohorts based on their reported career aspirations. After a pre-test questionnaire, subjects were tested on several urologic surgical skills: laparoscopy, cystoscopy and robotic surgery. Statistical analysis was performed using chi-squared test, student t-tests and Spearman's correlation where appropriate.

Results: A total of 29 students participated in the study and no significant baseline differences were found between cohorts with respect to demographics and prior surgical experience. For laparoscopic skills, the surgical cohort outperformed the non-surgical cohort on several exercises: Lap Beans Missed (4.9 vs. 9.3, $p<0.01$ ), Lap Bean Rating (3.8 vs. 3.1, $p=0.01$ ), Lap Rings Error (0.2 vs. 1.22, $p<0.01)$, Lap Rings Rating (3.9 vs. $2.9, p<0.01)$ and LapSim Grasping Score (64.3 vs. 46.4, $p=0.01)$. For cystoscopic skills, there were no significant differences between cohorts on any of the performance metrics. The surgical cohort also outperformed the non-surgical cohort on all measured robotic surgery performance metrics: Task Time (50.6 vs. 76.3, $p<0.01)$, Task Errors $(0.2$ vs. 3.1, $p<0.01)$, and Task Score (89.5 vs. 72.6, $p<0.01)$.

Discussion: Objective innate technical ability in urological skills, particularly laparoscopy and robotics, may differ between early trainees interested in a surgical career compared to those interested in a non-surgical career. Further studies are required to illicit what impact such differences have on future performance and competence.

\section{Introduction}

Medicine has become drastically more advanced over the past few decades, particularly within the surgical field. There has been a strong shift towards increased utilization of minimally invasive surgeries, requiring physicians to improve upon their technical skill and progress through often steep learning curves. ${ }^{1,2}$ Urology has been at the forefront of this paradigm change. Early surgical trainees and medical students are experiencing it first-hand with exposure to innovative technologies, such as laparoscopy, robotics and thermal ablation techniques. ${ }^{2-4}$

Medical students have many career choices to make throughout the course of their education. One of the earlier decisions is whether to pursue a career in a surgical or nonsurgical field. Several studies have examined and proposed various innate differences between medical students and how these differences may influence their choice in selecting different career paths. ${ }^{5,6}$ However, there is a scarcity of literature deciphering the role of innate technical ability and how it may affect both trainee selection of career choice as well as their future ability to succeed within a surgical discipline. Do students interested in a surgical career path possess greater innate technical ability? Johnson and colleagues ${ }^{7}$ studied the influence that innate characteristics have on a person's ability and they revealed that once error rates reach a steady state, innate ability was often responsible for limitations in performance. However, understanding the role of innate technical skill is made even harder as predictors of innate technical ability are not well-described. ${ }^{8}$

In this study, we determine whether there are differences in objective innate technical ability, specific to urologic surgery, between medical students of varying career interests. 


\section{Methods}

Medical students from the University of Toronto who had just completed their first year of training were approached to participate in this study; we included students enrolled in a University of Toronto surgical interest group (Surgical Exploration And Discovery program $)^{9}$ called the "surgical cohort" and students interested in a non-surgical field termed the "non-surgical cohort." The non-surgical group was determined using a questionnaire outlining current career choices; those with top 3 career choices that were non-surgical were approached for participation in the study. Informed written consent was obtained from all 29 participants prior to the study.

A pre-study questionnaire regarding various demographic data was administered to each participant. This questionnaire also included an assessment of prior surgical exposure and experience, as well as self-reported scores of dexterity and surgical technical skills.

Each participant then underwent baseline skill testing involving 3 common urological skills: laparoscopy, cystoscopy and robotic surgery. Prior to skill testing, each participant was given a brief 5-minute hands-on introduction on the specific instruments and skills and they were given the chance to practice the skills being assessed. The order in which each of the 3 technical skills was assessed was random. All performance scores for each of the 3 urological skills were provided by the same station proctor for all participants.

\section{Laparoscopy}

Laparoscopic skills were assessed using both a generic laparoscopic box trainer and a validated VR simulator (LapSim, Surgical Science, Sweden). ${ }^{10,11}$

Participants were asked to transfer various objects within the laparoscopic box training using standard Maryland laparoscopic graspers. The "Lap Beans" exercise involved picking up beans from a small tray and placing as many as possible accurately into a small hole at the top of a cup. After a 1-minute practice session, participants were assessed on how many beans were successfully placed into the cup and how many were dropped over a 5-minute testing interval. Upon completion of the "Lap Beans" exercise, each student was given a performance rating ( 1 to 5 ) by a station proctor. The "Lap Rings" exercise involved picking up and moving 6 rubber rings from one side of a peg board to another. After a single practice attempt, participants were assessed on the total time it took to transfer all 6 rings, the total number of errors (dropped rings, instrument clashes), and were also given a performance rating ( 1 to 5 ) by the station proctor.

Participants then completed 2 different exercises on the LapSim simulator. Skill testing occurred only after each participant had the opportunity to practice a standardized task ("Coordination task"). Using built-in scoring software, participants were assessed on their performance of the "Navigation task" and the "Grasping task."

\section{Cystoscopy}

Cystoscopic skills were assessed using the URO Mentor (Simbionix, Israel) simulator. ${ }^{12,13}$ After a brief introduction and a hands-on practice session, participants were assessed on their ability to perform rigid cystoscopy, catheterization of the right ureteric orifice and a retrograde pyelogram. The total time to complete the task, number of attempts to catheterize the right orifice, and total fluoroscopy time required were all assessed by the built-in simulator software. An overall performance rating ( 1 to 5 ) was also provided upon completion of the cystoscopic task by the station proctor.

\section{Robotic surgery}

Robotic surgical skills were assessed using the daVinci Skills Simulator (dVSS, Intuitive Surgical, Sunnyvale, CA). ${ }^{14}$ After a standardized introduction to the daVinci robot (Si model) and completing a standardized practice task ("Peg Board 1 "), participants were assessed on the "Pick and Place" task, which involved the transfer of objects from one location to another. Using the built-in dVSS software, we assessed the total time required to complete the task, the number of errors committed, and an overall performance score.

\section{Statistics}

Data analysis was performed using chi-squared test, student t-tests and Spearman's correlation where appropriate. A $p$ value of less than 0.05 was considered significant. Statistical analysis was performed using SPSS v. 21 (IBM Corp., Armonk, NY).

\section{Results}

A total of 29 medical students from the University of Toronto completed the study: there were 20 in the "surgical cohort" and 9 in the "non-surgical cohort."

There were no significant differences between the surgical and non-surgical cohorts with respect to gender, handedness, video game use, sports participation, prior open suturing exposure, prior cystoscopy exposure, prior laparoscopic surgery exposure, prior robotic surgery exposure, mean selfreported dexterity score and mean self-reported surgical skill score (Table 1). In addition to similar surgical exposure between groups, there was no difference in mean selfreported surgical skill $(2.6 \pm 0.75$ vs. $2.6 \pm 0.73, p=0.88)$ or mean self-reported dexterity $(3.4 \pm 0.88$ vs. $3.7 \pm 1.22$, $p=0.51)$ between the 2 cohorts. 
Gupta et al.

\begin{tabular}{|c|c|c|c|}
\hline & Surgical students & Non-surgical students & $p$ value ${ }^{*}$ \\
\hline Total & 20 & 9 & \\
\hline Male & $12(60 \%)$ & $5(56 \%)$ & 0.82 \\
\hline Right-hand dominant $(\%)^{+}$ & $18(90 \%)$ & $9(100 \%)$ & 0.33 \\
\hline Don't play video games ${ }^{+}$ & $6(30 \%)$ & $4(44 \%)$ & 0.39 \\
\hline Don't play sports ${ }^{+}$ & $6(30 \%)$ & $3(33 \%)$ & 0.53 \\
\hline No prior open suturing exposure ${ }^{+}$ & $2(10 \%)$ & $4(44 \%)$ & 0.91 \\
\hline No prior cystoscopy exposure ${ }^{+}$ & $18(90 \%)$ & $9(100 \%)$ & 0.33 \\
\hline No prior laparoscopic surgery exposure ${ }^{+}$ & $4(20 \%)$ & $5(56 \%)$ & 0.13 \\
\hline No prior robotic surgery exposure ${ }^{+}$ & $13(65 \%)$ & $8(89 \%)$ & 0.18 \\
\hline Mean self-reported dexterity score (range: $1-5)^{*}$ & $3.4 \pm 0.88$ & $3.7 \pm 1.22$ & 0.51 \\
\hline Mean self-reported surgical skill score (range: $1-5)^{*}$ & $2.6 \pm 0.75$ & $2.6 \pm 0.73$ & 0.88 \\
\hline
\end{tabular}

On urologic surgical skills assessment, there were significant differences on certain tasks (Table 2). For laparoscopic skills, the surgical cohort outperformed the non-surgical cohort in Lap Beans Missed (4.9 vs. 9.3, $p<0.01$ ), Lap Bean Rating (3.8 vs. 3.1, $p=0.01)$, Lap Rings Error (0.2 vs. $1.22, p<0.01$ ), Lap Rings Rating (3.9 vs. $2.9, p<0.01$ ), and LapSim Grasping Score (64.3 vs. 46.4, $p=0.01$ ). For cystoscopic skills, there were no significant differences between cohorts in any of the tasks completed. For robotic skills, the Task Time (50.6 vs. $76.3, p<0.01)$, Task Errors $(0.2$ vs. $3.1, p<0.01)$, and Task Score (89.5 vs. 72.6, $p<0.01)$ all differed significantly between the 2 groups, with the surgical cohort consistently outperforming the non-surgical cohort.
Prior laparoscopic, cystoscopic, and robotic surgery exposure/experience did not predict better performance on any of the variables assessed, nor did prior video-game play $(p>0.05)$. Interestingly, significant participation in sports correlated with improved performance on the robotic surgical skill task, in terms of time $(p=0.02)$ and overall score $(p=0.04)$.

\section{Discussion}

In an effort to attract the best medical students to our specialty and to discern which students may become successful urology trainees, and ultimately urologic surgeons, many

\begin{tabular}{|c|c|c|c|}
\hline & Surgical students & Non-surgical students & $p$ value ${ }^{*}$ \\
\hline \multicolumn{4}{|l|}{ Laparoscopic skills } \\
\hline Lap Beans In & 16.8 & 16.3 & 0.90 \\
\hline Lap Beans Missed & 4.9 & 9.3 & $<0.01$ \\
\hline Lap Beans Rating (range 1-5) & 3.8 & 3.1 & 0.01 \\
\hline Lap Rings Time (sec) & 49.5 & 67.7 & 0.05 \\
\hline Lap Rings Errors & 0.2 & 1.33 & $<0.01$ \\
\hline Lap Rings Rating (range 1-5) & 3.9 & 2.9 & $<0.01$ \\
\hline LapSim Nav Errors & 1.1 & 1.6 & 0.45 \\
\hline LapSim Nav Score (0-100) & 81.3 & 72.6 & 0.21 \\
\hline LapSim Grasp Errors & 3.6 & 6.8 & 0.05 \\
\hline LapSim Grasp Score (0-100) & 64.3 & 46.4 & 0.01 \\
\hline Cystoscopy skills & Cystoscopy skills & & \\
\hline UroMentor Time (sec) & 151.1 & 142.8 & 0.79 \\
\hline UroMentor Attempts & 2.4 & 2.6 & 0.90 \\
\hline UroMentor Fluoro Time (sec) & 6.5 & 6 & 0.87 \\
\hline UroMentor Rating ( 1 to 5 ) & 3.2 & 3 & 0.67 \\
\hline Robotic skills & Robotic skills & & \\
\hline Task Time (sec) & 50.6 & 76.3 & $<0.01$ \\
\hline Task Errors & 0.2 & 3.1 & $<0.01$ \\
\hline Task Score (0-100) & 89.5 & 72.6 & $<0.01$ \\
\hline
\end{tabular}


educators have attempted to detect baseline differences between these early trainees that may predict future performance. However, it still remains unclear whether there are any innate differences between students interested in surgical and non-surgical career paths.

To our knowledge, this is the first study to examine whether a difference exists in innate urologic surgical technical ability between medical students interested in surgery and those interested in other non-surgical specialties.

Our study demonstrates that there is a significant difference in objective innate technical ability between the surgical and non-surgical groups, particularly for laparoscopic and robotic skills. Interestingly, however, there was no significant difference in perceived innate technical ability between our 2 cohorts. The surgical cohort performed significantly better, or demonstrated a trend towards better performance, than the non-surgical cohort on all laparoscopic tasks and also outperformed on the robotic task with respect to all study performance parameters.

The exact cause behind this finding cannot be deciphered from this study alone, but it may demonstrate an innate difference in visual spatial perception or psychomotor learning curves between the 2 groups. Visual spatial perception has been considered an important component of surgical competence. Risucci and colleagues ${ }^{15}$ have found that surgeons tend to outperform the general population on tests of high-level visual spatial perception abilities. It was also shown by Van Herzeele and colleagues ${ }^{16}$ that perceptual, visuospatial and psychomotor aptitude correlated with initial and end performance during simulated complex endovascular interventions. In addition, learning curves at higher levels of training have been shown to be an important predictor of performance on laparoscopic simulators. Grantcharov and colleagues ${ }^{17}$ discovered that different learning curves exist between surgeons at different levels of experience. Combining these theories, Stefanidis and colleagues ${ }^{18}$ add that the importance of psychomotor testing lies in its prediction of the rapidity of skill acquisition. These results can be translated to medical students at an early level of training, and a combination of these is likely responsible for the aforementioned results.

There was no significant difference in the cystoscopy skill task between the 2 groups. It can be speculated that this finding was due to either insufficient instruction and/or increased difficulty of the task. The cystoscopic task used for assessment, though considered a relatively novice skill for urologists, is likely a very complex task for junior medical students. In addition, almost all students involved in the study had no prior exposure to cystoscopy, which may have limited their ability to build on prior knowledge, a critical component of skills acquisition.

This study is limited mainly by its small sample size. Only a total of 29 students participated; there were 9 students in the non-surgical cohort. Also, the 20 students in the surgical cohort were participating in the SEAD program, thereby limiting the study's generalizability to the whole institution. The skill tasks selected for assessment, though used in other existing training curricula and validated as part of other assessments, may not have fully captured any true differences between cohorts. Though the order was random, we were also not able to control for the different order in which each participant completed the 3 skill tasks, and how this may have affected specific performances.

To fully determine the impact of the differences in innate technical ability, future study is required in which these students are followed into residency training and their future performance is correlated with baseline skill levels. Finally, although the tasks completed in this study were selected by experts in the field, there are no accepted metrics for a students' aptitude for urology surgical skills. ${ }^{19}$

\section{Conclusion}

A difference in objective innate technical ability for urologic surgical skills, particularly laparoscopic and robotic surgery, may be present among medical students pursuing a surgical career and those pursuing a non-surgical career. These findings need to be validated in larger scale studies and further investigations are required to determine the impact of such innate differences on future performance.

Competing interests: Mr. Gupta, Dr. Lantz, Dr. Alzharani and Dr. Foell declare no competing financial or personal interests. Dr. Lee received a grant from Takeda Inc in 2012.

This paper has been peer-reviewed.

\section{References}

1. Gallagher AG, Smith CD. From the operating room of the present to the operating room of the future. Human-factors lessons learned from the minimally invasive surgery revolution. Semin Laparosc Surg 2003;10:127-39.

2. Marohn MR, Hanly EJ. Twenty-first century surgery using twenty-first century technology: Surgical robotics. Curr Surg 2004;61:466-73. http://dx.doi.org/10.1016/i.cursur.2004.03.009

3. Amodeo A, Linares Quevedo A, Joseph JV, et al. Robotic laparoscopic surgery: Cost and training. Minerva Urol Nefrol 2009;61:121-8.

4. Guzzo TJ, Gonzalgo ML. Robotic surgical training of the urologic oncologist. Urol Oncol 2009;27:214-7. http://dx.doi.org/10.1016/i.urolonc.2008.09.019

5. Lee JY, Kerbl DC, McDougall EM, et al. Medical students pursuing surgical fields have no greater innate motor dexterity than those pursuing nonsurgical fields. J Surg Educ 2012;69:360-3. http://dx.doi. org/10.1016/i.surg.2011.11.005

6. Scott IM, Matejek AN, Gowans MC, et al. Choosing a career in surgery: Factors that influence Canadian medical students' interest in pursuing a surgical career. Can I Surg 2008:51:371-7.

7. Johnson DB, Kondraske GV, Wilhelm DM, et al. Assessment of basic human performance resources predicts the performance of virtual ureterorenoscopy. J Urol 2004;171:80-4. http://dx.doi.org/10.1097/01. ju.0000100167.92139.cb

8. Van Hove C, Perry KA, Spight DH, et al. Predictors of technical skill acquisition among resident trainees in a laparoscopic skills education program. World J Surg 2008;32:1917-21. http://dx.doi.org/10.1007/ s00268-008-9643-4 
Gupta et al.

9. Gawad N, Moussa F, Christakis GT, et al. Planting the 'SEAD': Early comprehensive exposure to surgery for medical students. J Surg Educ 2013;70:487-94. http://dx.doi.org/10.1016/i.jsurg.2013.03.006

10. van Dongen KW, Tournoij E, van der Zee DC, et al. Construct validity of the LapSim: Can the LapSim virtual reality simulator distinguish between novices and experts? Surg Endosc 2007;21:1413-7. http:// dx.doi.org/10.1007/s00464-006-9188-2

11. Duffy AJ, Hogle NJ, MCCarthy H, et al. Construct validity for the LAPSIM laparoscopic surgical simulator. Surg Endosc 2005;19:401-5. http://dx.doi.org/10.1007/s00464-004-8202-9

12. Shah J, Darzi A. Virtual reality flexible cystoscopy: A validation study. BJU Int 2002;90:828-32. http:// dx.doi.org/10.1046/j.1464-410X.2002.03090.x

13. Shah J, Montgomery B, Langley S, et al. Validation of a flexible cystoscopy course. BJU Int 2002;90:8335. http://dx.doi.org/10.1046/j.1464-410X.2002.03089.x

14. Alzahrani T, Haddad R, Alkhayal A, et al. Validation of the daVinci Surgical Skill Simulator across three surgical disciplines: A pilot study. Can Urol Assoc J 2013;7:E520-9. http://dx.doi.org/10.5489/cuai.419

15. Risucci DA. Visual spatial perception and surgical competence. Am I Surg 2002;184(3):291-295. http:// dx.doi.org/10.1016/S0002-9610(02)00937-6
16. Van Herzeele I, $\mathrm{O}^{\prime}$ Donoghue $\mathrm{KG}$, Aggarwal R, et al. Visuospatial and psychomotor aptitude predicts endovascular performance of inexperienced individuals on a virtual reality simulator. J Vasc Surg 2010;51:103542. http://dx.doi.org/10.1016/i.jus.2009.11.059

17. Grantcharov TP, Bardram L, Funch-Jensen $P$, et al. Learning curves and impact of previous operative experience on performance on a virtual reality simulator to test laparoscopic surgical skills. Am I Surg 2003;185:146-9. http://dx.doi.org/10.1016/S0002-9610(02)01213-8

18. Stefanidis D, Korndorffer JR Jr, Black FW, et al. Psychomotor testing predicts rate of skill acquisition for proficiency-based laparoscopic skills training. Surgery 2006;140:252-62. http://dx.doi.org/10.1016/i. surg.2006.04.002

19. Madan AK, Frantzides CT, Sasso LM. Laparoscopic baseline ability assessment by virtual reality. J Laparoendosc Adv Surg Tech A 2005;15:13-7. http://dx.doi.org/10.1089/lap.2005.15.13

Correspondence: Dr. Jason Y. Lee, 61 Queen St. E. - Suite 9-103, Toronto, ON M5C 2T2; leejasoSMH@gmail.com 